\title{
Application of a sea surface roughness formula using joint statistics of significant wave height and spectral wave steepness
}

\author{
Dag Myrhaug $^{1}$ (D) Bernt J. Leira ${ }^{1} \cdot$ Wei Chai ${ }^{1}$
}

Received: 2 September 2019 / Accepted: 28 January 2020 / Published online: 14 February 2020

(c) The Author(s) 2020

\begin{abstract}
This article provides some statistical features of the sea surface roughness given as a function of the spectral wave steepness and the significant wave height suggested by Taylor and Yelland (J Phys Oceanogr 31:572-590, 2001), which is best to use for mixed wind sea and swell, and for swell-dominated situations (Drennan et al., J Phys Oceanogr 35:835-848, 2005). Results are obtained using the Myrhaug and Fouques (2008) bivariate statistics of the spectral wave steepness and the significant wave height representing wind sea, swell, and combined wind sea and swell. Associated results are also given for the sea surface drag coefficient and the turbulent energy density, as well as a procedure of estimating the sea surface roughness from 1-, 10- and 100-year contour lines. Finally, a simple example of application is given, demonstrating the effect of the sea surface roughness on slowly varying surge motion of marine structures exposed to wind gust.
\end{abstract}

Keywords Sea surface roughness - Significant wave height $\cdot$ Spectral wave steepness . Bivariate distributions . Contour lines $\cdot$ Logarithmic mean wind speed profile $\cdot$ Wind gust spectrum $\cdot$ Slowly varying surge motion

\section{Introduction}

The sea surface roughness depends on the mechanisms of air-sea interaction and its estimation is difficult; no consistent theory exists covering the range from small waves to big waves including wind waves, combined wind waves and swell, as well as swell. Charnock (1955) presented his formula based on a dimensional argument, i.e. the sea surface roughness $z_{0}=\beta u_{*}^{2} / g$, where the original Charnock parameter is $\beta=0.012$, and $u_{*}$ is the friction velocity. Since then, many different values of $\beta$ as well as formulae for $z_{0}$ have been proposed, also containing the wind speed as a parameter; see, e.g. Jones and Toba (2001) for a review.

Drennan et al. (2005) performed a comprehensive intercomparison of different parameterizations of the sea surface roughness using field data from eight locations ranging from lakes to deep-water sea. They found that if bulk sea state parameters such as significant wave height and spectral peak period are available, then the roughness formula as a func-

\footnotetext{
Dag Myrhaug

dag.myrhaug@ntnu.no

1 Department of Marine Technology, Norwegian University of Science and Technology (NTNU), Otto Nielsens vei 10 , 7491 Trondheim, Norway
}

tion of the spectral wave steepness and the significant wave height proposed by Taylor and Yelland (2001) [see Eq. (1)] was the best to use for mixed wind sea and swell, and for swell-dominant situations (see Drennan et al. (2005) for more details). A recent review of the literature is provided by Zhao and Li (2019), followed by presenting results from a comprehensive analysis of the influence of wind waves on wind stress with respect to sea surface roughness and drag coefficient based on both laboratory and field data. In the pioneering work of Powell et al. (2003) and Zhao and Li (2019) it was found that the drag coefficient reaches a peak for strong winds, i.e. for wind speeds exceeding $30-40 \mathrm{~m} / \mathrm{s}$. Zhao and $\mathrm{Li}$ (2019) also found that a roughness formula in terms of the spectral wave steepness and the significant wave height can be applied to estimate wind stress from low to high winds (see Sect. 2). Myrhaug (2020) demonstrated how this sea surface roughness formula for wind sea can be applied to estimate the sea surface roughness based on wind and wave statistics.

Some recent works related to load assessment studies for offshore wind power systems have advocated the use of the Hsu (1974) relationship for $z_{0}$ where the sea surface roughness depends on the wave conditions, taking the Charnock parameter equal to the wave steepness $s$, i.e. $\beta=s=H / \lambda$, where $H$ is the wave height and $\lambda$ is the wave length. This 
was adopted and used for shallow-water waves by Donkers et al. (2011) and Kalverla et al. (2017) as part of an extensive analysis of wind conditions in the Dutch part of the southern North Sea. Furthermore, Myrhaug (2018) presented some statistical properties of the deep-water wave steepness and the spectral wave steepness based on measured wave data from the Norwegian continental shelf, which, therefore, is related to the Hsu (1974) sea surface roughness.

The sea surface roughness enters in the description of the local wind conditions over the sea surface, i.e. using a logarithmic mean wind speed profile plus a wind gust spectrum; see, e.g. Myrhaug and Ong (2009) who investigated the wave age effect on wind gust spectra for wind waves. Many wind gust spectra have been proposed, see, e.g. Chakrabarti (1990). It is well established that wind gust spectra over sea contain more energy at lower frequencies than those over land [see, e.g. Ochi and Shin (1988), Andersen and Løvseth (2006)]. This spectral property is essential when assessing the response, e.g. of moored ships and structures which are sensitive to excitations at low frequencies.

The main purpose and the novelty of the present article is to demonstrate how the Myrhaug and Fouques (2008) bivariate statistics of the spectral wave steepness and the significant wave height representing wind sea, swell, and combined wind sea and swell can be used to obtain statistical properties of the sea surface roughness for sea states given by Taylor and Yelland (2001), which are best to use for mixed wind sea and swell and for swell-dominated situations. This is relevant to the assessment of local wind conditions at sea, e.g. related to wind load studies on marine structures. The Taylor and Yelland (2001) sea surface roughness is adopted due to its compromise between simplicity and robustness. It is also demonstrated how these results affect the local wind conditions described by the logarithmic mean wind speed profile plus the Ochi and Shin (1988) wind gust spectrum. An example of the application is also included.

This article is structured as follows: this section is followed by Sect. 2 describing the background of the Taylor and Yelland (2001) sea surface roughness formula, the logarithmic mean wind speed profile, and the Ochi and Shin (1988) wind gust spectrum. Section 3 presents the application of the Myrhaug and Fouques (2008) bivariate statistics of the spectral wave steepness and the significant wave height by yielding some probabilistic features of sea surface roughness (Sect. 3.1); sea surface drag coefficient and turbulence energy density (Sect. 3.2); estimation of sea surface roughness from $n$-year return period contour lines (Sect. 3.3); an application related to the effect of the sea surface roughness on slowly varying surge motion of marine structures exposed to wind gust (Sect. 3.4). A summary is provided in Sect. 4.

\section{Background}

Following Taylor and Yelland (2001), the sea surface roughness is given as

$\frac{z_{0}}{H_{s}}=c s_{p}^{d} ; \quad(c, d)=(1200,4.5)$,

where $H_{s}$ is the significant wave height, $s_{p}=$ $H_{s} /\left((g / 2 \pi) T_{p}^{2}\right)$ is the spectral wave steepness, $g$ is the acceleration of gravity, and $T_{p}$ is the spectral peak period. According to Drennan et al. (2005), Eq. (1) is good for conditions representing mixed wind sea and swell and swelldominated conditions for $s_{p}>0.02$. As referred to in Sect. 1 , Zhao and $\mathrm{Li}$ (2019) found that $z_{0}$ in terms of $s_{p}$ and $H_{s}$ can be applied to estimate wind stress for wind sea from low to high winds, i.e. to use Eq. (1) with $(c, d)=(2.79,2.77)$.

The mean wind speed profile for a neutrally stable atmospheric boundary layer (i.e. by neglecting temperature gradient effects, which is the case for strong wind) is described by the logarithmic profile

$$
\frac{U(z)}{U_{10}}=2.5 \sqrt{C_{10}} \ln \frac{z}{z_{0}},
$$

where $U(z)$ is the horizontal mean wind speed at the elevation $z$ above the sea surface, $z$ is the vertical coordinate with $z=0$ at the sea surface and positive upwards, $U_{10}$ is the mean wind speed at $z=10 \mathrm{~m}$ and $C_{10}=\left(u_{*} / U_{10}\right)^{2}$ is the sea surface drag coefficient. Now $C_{10}$ and $z_{0}$ are related by taking $z=10 \mathrm{~m}$ in Eq. (2), as

$C_{10}=0.16\left(\ln \frac{10}{z_{0}}\right)^{-2}$

where $z$ is given in metres.

The wind gust is modelled as a Gaussian random process and thus described by the wind gust spectrum $S(f)$, with $f$ as the frequency in $H z=s^{-1}$. In this article, the horizontal component of the wind gust component in the same direction as $U_{z}=U(z)$ is considered, exemplified by adopting the Ochi and Shin (1988) spectrum:

$S\left(f_{*}\right)= \begin{cases}583 f_{*} & \text { for } 0 \leq f_{*} \leq 0.003 \\ \frac{420 f_{*}^{0.70}}{\left(1+f_{*}^{0.35}\right)^{11.5}} & \text { for } 0.003 \leq f_{*} \leq 0.1 \\ \frac{838 f_{*}}{\left(1+f_{*}^{0.35}\right)^{11.5}} & \text { for } 0.1 \leq f_{*}\end{cases}$

where the dimensionless frequency is $f_{*}=f z / U_{z}$ and the dimensionless spectrum is $S\left(f_{*}\right)=f S(f) / u_{*}^{2}$, which also is valid for neutrally stable atmospheric conditions. Further- 
more, here $f S(f)$ is the turbulence energy density, which can be expressed in dimensionless form as

$\frac{f S(f)}{U_{10}^{2}}=C_{10} S\left(f_{*}\right)$

using $u_{*}^{2}=C_{10} U_{10}^{2}$.

The results of using these local wind formulae are elaborated further in Sect. 3.

\section{Use of the Myrhaug and Fouques (2008) bivariate statistics of $H_{s}$ and $s_{p}$}

\subsection{Some statistical features of $z_{0}$}

Here the Myrhaug and Fouques (2008) (hereafter referred to as MF08) joint probability density function ( $p d f)$ of $H_{S}$ and $s_{p}$ will be used. This $p d f$ originates from best fit to data from the northern North Sea representing wave states containing wind sea, swell, and combined wind sea and swell. Thus, there is consistency in using this $p d f$ and Eq. (1) since both represent similar wave conditions. It should be noted that the results presented in Sect. 3.1-3.3 are solely based on wave statistics. However, use of these results involving $U_{10}$ should be for $U_{10}$ less than about $30 \mathrm{~m} / \mathrm{s}$.

The MF08 joint $p d f$ is given as

$p\left(H_{s}, s_{p}\right)=p\left(s_{p} \mid H_{S}\right) p\left(H_{S}\right)$,

where $p\left(H_{S}\right)$ is the marginal $p d f$ of $H_{S}$ given as a combined lognormal and Weibull distribution (see Eq. (2) in MF08), and $p\left(s_{p} \mid H_{s}\right)$ is the conditional $p d f$ of $s_{p}$ given $H_{s}$, given as the lognormal $p d f$ :

$p\left(s_{p} \mid H_{S}\right)=\frac{1}{\sqrt{2 \pi} \sigma s_{p}} \exp \left[-\frac{\left(\ln s_{p}-\mu\right)^{2}}{2 \sigma^{2}}\right]$.

The conditional expected value $\mu$ and the conditional variance $\sigma^{2}$ of $\ln s_{p}$ are

$\mu=\ln \left(\frac{H_{s}}{g / 2 \pi}\right)-2\left(a_{1}+a_{2} H_{s}^{a_{3}}\right)$,

$\left(a_{1}, a_{2}, a_{3}\right)=(1.780,0.288,0.474)$,

$\sigma^{2}=b_{1}+b_{2} e^{b_{3} H_{s}}$,

$\left(b_{1}, b_{2}, b_{3}\right)=(0.001,0.097,-0.255)$.

Here $H_{S}$ is in metres in Eqs. (8) and (10) (see MF08 for further background and details).

Now the statistical features of $z_{0}$ are derived using this joint $p d f$ of $H_{s}$ and $s_{p}$.
First, by a change of variables from $\left(H_{s}, s_{p}\right)$ to $\left(H_{s}, z_{0}\right)$, the joint $p d f$ of $H_{s}$ and $z_{0}$ becomes

$p\left(H_{S}, z_{0}\right)=p\left(z_{0} \mid H_{S}\right) p\left(H_{S}\right)$.

Thus, only $p\left(s_{p} \mid H_{S}\right)$ is affected since $s_{p}=\left(z_{0} / c H_{s}\right)^{\frac{1}{d}}$, which gives a lognormal $p d f$ of $z_{0}$ given $H_{S}$ as (i.e. using the Jacobian $\left.\left|\partial s_{p} / \partial z_{0}\right|=z_{0}^{\frac{1}{d}-1} / d\left(c H_{S}\right)^{\frac{1}{d}}\right)$

$p\left(z_{0} \mid H_{S}\right)=\frac{1}{\sqrt{2 \pi} \sigma_{z} z_{0}} \exp \left[-\frac{\left(\ln z_{0}-\mu_{z}\right)^{2}}{2 \sigma_{z}^{2}}\right]$.

The conditional expected value $\mu_{z}$ and the conditional variance $\sigma_{z}^{2}$ of $\ln z_{0}$ are

$\mu_{z}=d \mu+\ln \left(c H_{s}\right)$

$\sigma_{z}^{2}=(d \sigma)^{2}$

where $\mu$ and $\sigma$ are given in Eqs. (8), (9) and (10), (11), respectively.

Second, the conditional expected value and the conditional variance of $z_{0}$ are obtained from the known $p\left(z_{0} \mid H_{s}\right)$ in Eq. (13) as (Bury 1975)

$E\left[z_{0} \mid H_{S}\right]=\exp \left(\mu_{z}+\frac{1}{2} \sigma_{z}^{2}\right)$,

$\operatorname{Var}\left[z_{0} \mid H_{s}\right]=\left(e^{\sigma_{z}^{2}}-1\right) \exp \left(2 \mu_{z}+\sigma_{z}^{2}\right)$.

Then it follows that the conditional coefficient of variation is

$\gamma\left[z_{0} \mid H_{s}\right]=\frac{\left(\operatorname{Var}\left[z_{0} \mid H_{S}\right]\right)^{1 / 2}}{E\left[z_{0} \mid H_{S}\right]}=\left(e^{\sigma_{z}^{2}}-1\right)^{1 / 2}$.

Figure 1 shows the ratio $E\left[z_{0} \mid H_{S}\right] / H_{S}$ versus $H_{s}$ according to Eq. (16). It appears that this ratio increases as $H_{S}$ increases, reaching a value of about 0.00032 for $H_{s}=15 \mathrm{~m}$.

Figure 2 shows the conditional coefficient of variation $\gamma\left[z_{0} \mid H_{s}\right]$ versus $H_{s}$ according to Eq. (18). It is seen that $\gamma\left[z_{0} \mid H_{S}\right]$ decreases as $H_{S}$ increases; from values in the range 2-2.5 for small $H_{s}$ to about 0.3 for $H_{s}=15 \mathrm{~m}$.

\subsection{Conditional statistical values of $C_{10}$ and turbulence energy density}

Figure 3 shows the sea surface drag coefficient $C_{10}$ versus $H_{S}$ according to Eq. (3) by substituting $E\left[z_{0} \mid H_{s}\right]$ from Eq. (16) for $z_{0}$. It is observed that $C_{10}$ increases as $H_{s}$ increases, from about 0.005 for small values of $H_{S}$ up to about 0.0027 for $H_{s}=15 \mathrm{~m}$.

Figure 4 shows $U(z) / U_{10}$ versus $z$ according to Eq. (2) for $H_{s}=3 \mathrm{~m}, 6 \mathrm{~m}, 9 \mathrm{~m}, 12 \mathrm{~m}$. At a given elevation below 


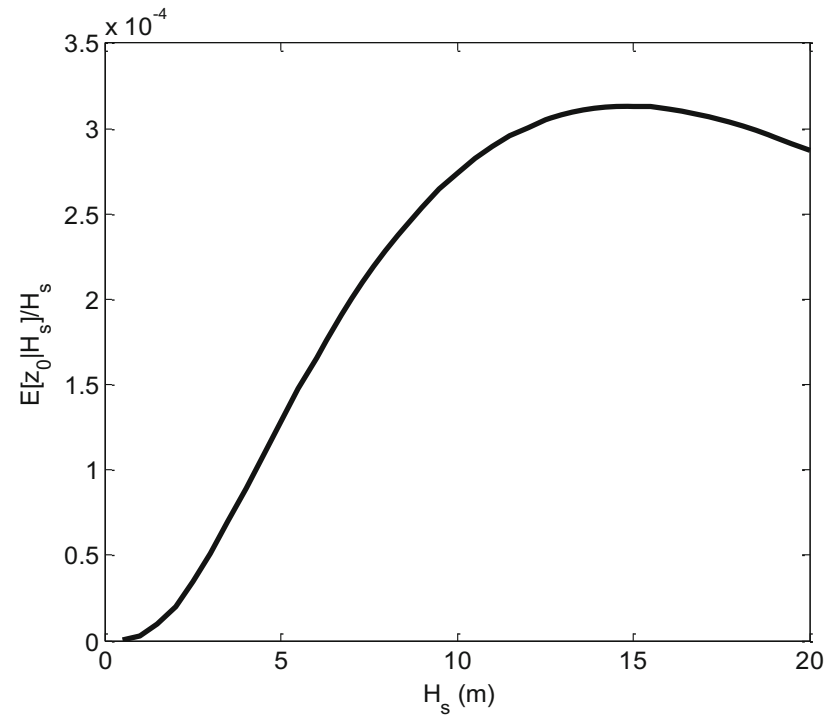

Fig. $1 E\left[z_{0} \mid H_{s}\right] / H_{s}$ versus $H_{s}$

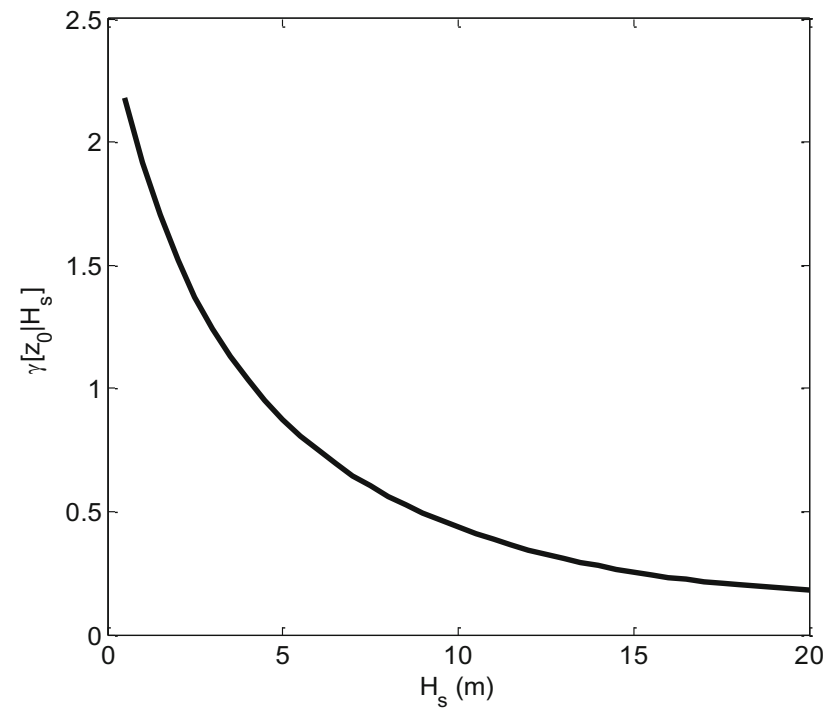

Fig. $2 \gamma\left[z_{0} \mid H_{S}\right]$ versus $H_{S}$

$z=10 \mathrm{~m}$, it appears that $U(z) / U_{10}$ decreases as $H_{S}$ increases from $3 \mathrm{~m}$ to $12 \mathrm{~m}$, which is due to that the sea surface roughness increases as $H_{S}$ increases. Moreover, at a given elevation above $z=10 \mathrm{~m}$, it is seen that $U(z) / U_{10}$ increases as $H_{S}$ increases from 3 to $12 \mathrm{~m}$, reflecting that the thickness of the logarithmic boundary layer increases as the sea surface roughness increases.

Figure 5 depicts the dimensionless turbulence energy density $f S(f) / U_{10}^{2}$ as a function of the dimensionless frequency $f_{*}$ according to Eq. (5) for $H_{s}=3 \mathrm{~m}, 6 \mathrm{~m}, 9 \mathrm{~m}, 12 \mathrm{~m}$, showing the increase of the turbulence energy as $H_{s}$ increases from 3 to $12 \mathrm{~m}$, i.e. the increase of the turbulence energy density as the sea surface roughness increases.

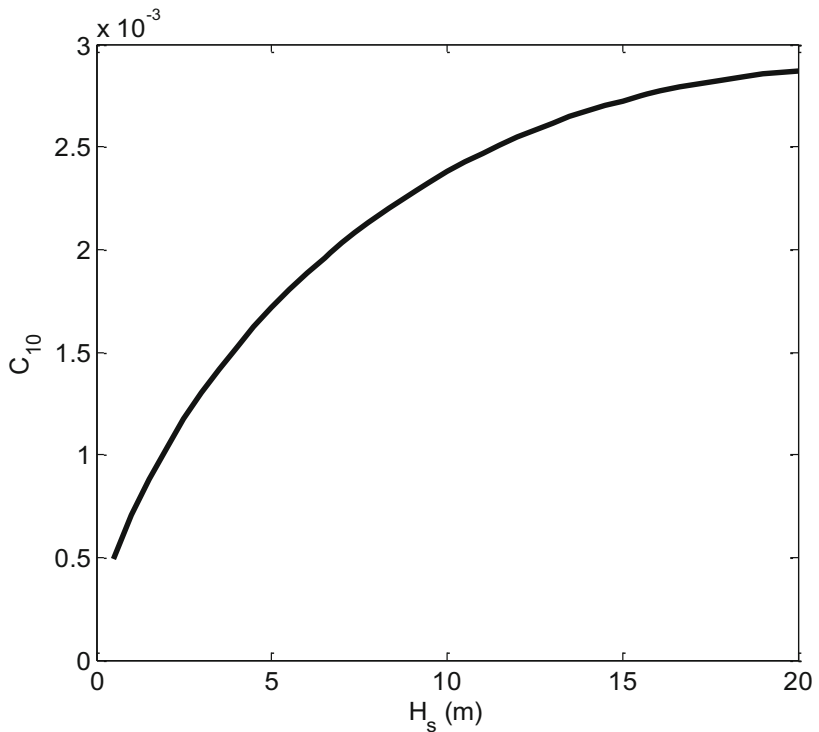

Fig. $3 C_{10}$ versus $H_{S}$

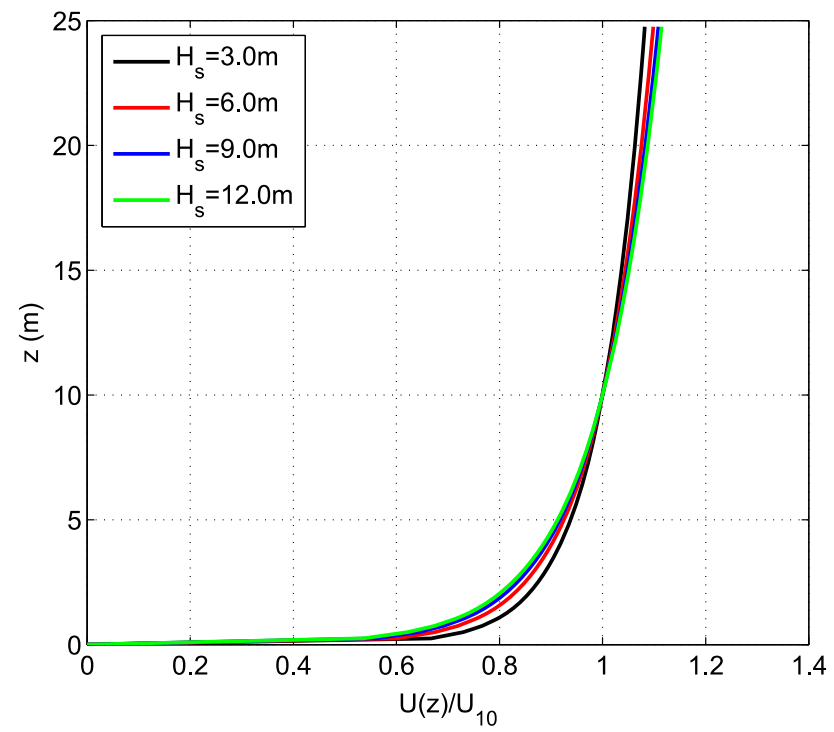

Fig. $4 U(z) / U_{10}$ versus $z$ for $H_{s}=3 \mathrm{~m}, 6 \mathrm{~m}, 9 \mathrm{~m}$ and $12 \mathrm{~m}$

\subsection{Estimation of $z_{0}$ based on contour lines of $H_{s}$ and $s_{p}$}

Figure 6, which is a re-plotted version of Fig. 13 in MF08, depicts the 1-, 10- and 100-year return period contour lines of $H_{s}$ and $s_{p}$ represented by the inner to the outer contours, respectively. MF08 determined these contour lines of $H_{s}, s_{p}$ based on a parametric model of a joint $p d f$ of $H_{s}$ and $T_{p}$ determined from a best fit to deep-water wave data measured in the northern North Sea during a period of 29 years (see MF08 for further details). 


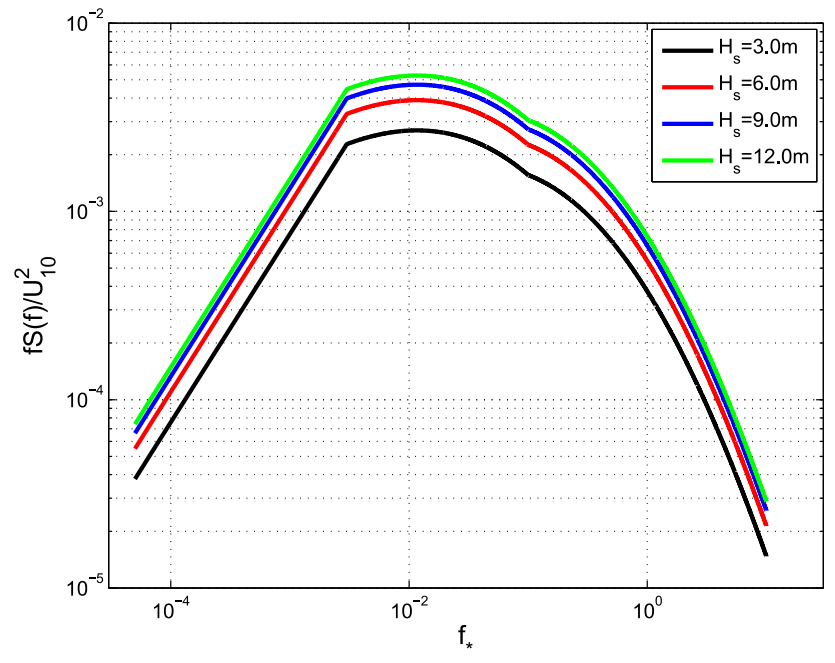

Fig. $5 f S(f) / U_{10}^{2}$ versus $f_{*}$ for $H_{s}=3 \mathrm{~m}, 6 \mathrm{~m}, 9 \mathrm{~m}$ and $12 \mathrm{~m}$

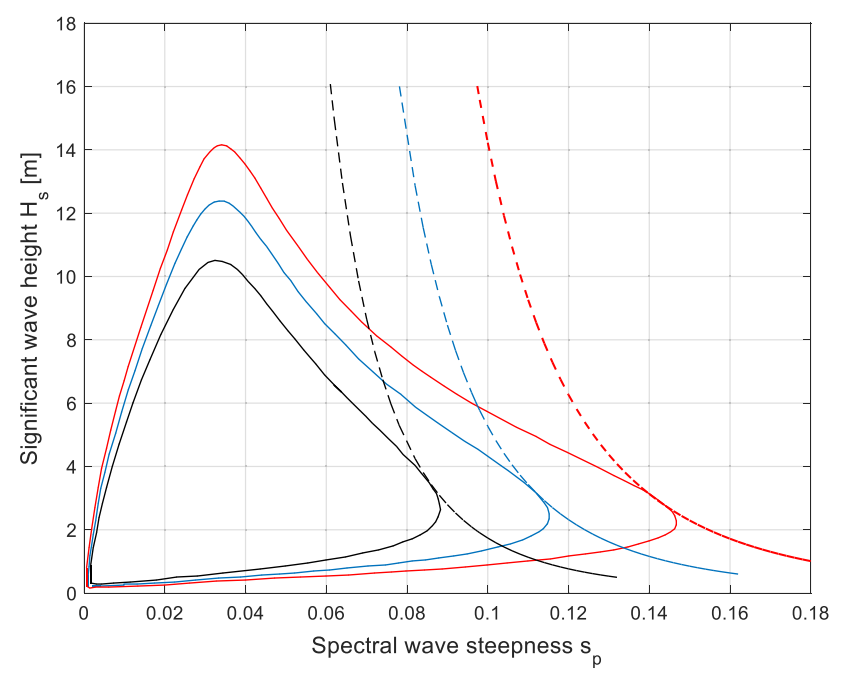

Fig. 6 1-Year, 10-year and 100-year contour lines of $H_{s}$ and $s_{p}$ from inner to outer contours, respectively. Tangent lines to the 1-, 10- and 100-year contour lines represent Eq. (19) with the corresponding $z_{0}$ values given in Table 1; the corresponding tangent points for $H_{s}, s_{p}$ are given in Table 1

Now the information in Fig. 6 is utilized by solving Eq. (1) for $H_{s}$, giving

$H_{s}=0.000833 z_{0} s_{p}^{-4.5}$.

For a given value of $z_{0}$, this is a curve in the $\left(H_{s}, s_{p}\right)$ plane. The values of $z_{0}$ imply that these curves will have tangent points with the 1-year, the 10-year and the 100year contours, which can be determined by iteration, and thus the corresponding tangent points. The results are shown graphically in Fig. 6 by the three curves giving tangent points to the 1-, 10- and 100-year contours for $z_{0}=$ $0.066 \mathrm{~m}, 0.20 \mathrm{~m}$, and $0.54 \mathrm{~m}$, respectively. Thus, these values correspond to the 1-, 10- and 100-year return period
Table 1 The 1-, 10- and 100 -year return period values of $z_{0}$ and the corresponding values of $H_{s}, s_{p}, C_{10}$ and $T_{p}$ corresponding to the results in Fig. 6

\begin{tabular}{llll}
\hline \multirow{3}{*}{ Variable } & \multicolumn{3}{l}{ Return period (years) } \\
\cline { 2 - 4 } & 1 & 10 & 100 \\
\hline$z_{0}(\mathrm{~m})$ & 0.066 & 0.20 & 0.54 \\
$H_{s}(\mathrm{~m})$ & 3.6 & 3.4 & 3.1 \\
$s_{p}$ & 0.085 & 0.11 & 0.14 \\
$C_{10}$ & 0.0064 & 0.011 & 0.019 \\
$T_{p}(s)$ & 5.2 & 4.4 & 3.8 \\
\hline
\end{tabular}

values of $z_{0}$. It is observed that these $z_{0}$ values based on the 1-, 10- and 100-year contour lines are governed by $s_{p}$ since the location of the tangent points is close to the maximum values of $s_{p}$ along the respective contour lines. The corresponding coordinates of the tangent points for $H_{s}, s_{p}$ are given in Table 1, together with the corresponding values of $C_{10}$ (Eq. 3) and $T_{p}$, where the latter is obtained from the definition of $s_{p}$ as

$T_{p}=\left(\frac{2 \pi H_{s}}{g s_{p}}\right)^{1 / 2}$

However, one should notice that these values of $H_{s}$ are far away from the peak values of $H_{S}$ along the contours, i.e. the peak value of $H_{S}$ along the 100-year return period contour line is about $14.1 \mathrm{~m}$. It is also noted that the values of $s_{p}$ are in the validity range of Eq. (1), i.e. $s_{p}>0.02$. Furthermore, from Eq. (5), it follows that the turbulence energy density is proportional to $C_{10}$. Thus, for the same values of $U_{10}$ and $f_{*}$, it appears from the values in Table 1 that the ratio between the 10-year and the 1-year values of the turbulence energy density is 1.7 ; the corresponding ratio between the 100-year and the 1-year values is 3.0.

\subsection{Example}

Here an example similar to that given in Myrhaug and Ong (2009) is chosen, demonstrating the effect of the 1-, 10and 100-year return period sea surface roughness values on slowly varying surge motion of structures caused by wind gust. In the Myrhaug and Ong (2009) example, the focus was on demonstrating the wave age effect on wind gust and the consequence for slowly varying surge motion of moored marine structures.

According to Faltinsen (1990), the variance of slowly varying surge motion of moored marine structures caused by wind gust is

$\sigma_{x}^{2}=\frac{1}{4 c b}\left(C_{D} A \rho_{a} U\right)^{2} S\left(f_{N}\right)$, 
where $c, b, C_{D}, A, \rho_{a}, U$ and $f_{N}$ denote the restoring coefficient, the damping coefficient, the drag coefficient, the frontal area against the wind, the air density, the mean wind speed and the natural frequency of surge motion, respectively.

The example applies Eq. (21) for $U=U_{10}=20 \mathrm{~m} / \mathrm{s}, z=$ $10 \mathrm{~m}, f_{N}=0.01 \mathrm{~Hz}$ and the Ochi and Shin spectrum in Eq. (4) for the 1-, 10- and 100-year conditions given in Table 1. Since $f_{* N}=0.01 \times 10 / 20=0.005$, the Ochi and Shin spectrum is given by the formula in Eq. (4) for $0.003 \leq f_{*} \leq 0.1$, which gives $S\left(f_{* N}\right)=1.93$ and thus, $S\left(f_{N}\right)=\left(C_{10} U_{10}^{2} / f_{N}\right) S\left(f_{* N}\right)$. For the same values of $c, b$, $C_{D}, A, \rho_{a}, U_{10}$ and $f_{N}$, it follows that $\sigma_{x}^{2}$ in Eq. (21) only depends on $C_{10}$, i.e. on $z_{0}$ according to Eq. (3). Consequently, using the results in Table 1, the 10- to 1-year ratio of $\sigma_{x}^{2}$ is 1.7 and the 100 - to 1 -year ratio of $\sigma_{x}^{2}$ is 3.0 , i.e. equal to the corresponding ratios for the turbulence energy density given in Sect. 3.3. Although simple, this example demonstrates how the present results can be used, and also illustrates clearly that the response of a moored marine structure that is sensitive to low-frequency excitations depends strongly on the sea surface roughness conditions.

\section{Summary}

Some statistical features of the Taylor and Yelland (2001) sea surface roughness defined as a function of the spectral wave steepness and the significant wave height are provided using the Myrhaug and Fouques (2008) bivariate statistics of these two sea state wave parameters. Other results for a given sea state include the surface drag coefficient, the logarithmic mean wind speed profile, and the turbulence energy density using the Ochi and Shin (1988) wind gust spectrum.

A procedure to determine the sea surface roughness based on the 1-, 10- and 100-year return period contour lines of $H_{S}$ and $s_{p}$ as well as the associated values of $H_{s}$ and $s_{p}$ is also given. The presented analytical approach can be applied to estimate the sea surface roughness based on available wave statistics.

Furthermore, an example is provided applying a formula for slowly varying surge motion of moored marine structures to illustrate the effect of wind gust using the 1-, 10- and 100 -year return period values of the sea surface roughness as input. It is demonstrated that compared to using the 1year value of the sea surface roughness, the variance of the surge motion increases by the factors 1.7 and 3.0 using the 10 -year and 100-year values of the sea surface roughness, respectively.

Although simple and limited to conditions representing mixed wind sea and swell, as well as swell-dominated conditions for the spectral peak steepness being larger than 0.02 , the present results should be useful for the assessment of local wind conditions at sea, e.g. relevant to wind load studies on marine structures. According to Zhao and $\mathrm{Li}$ (2019), the sea surface drag coefficient reaches a peak for wind speeds exceeding 30-40 m/s, and thus it is recommended to use the present results for wind speeds less than about $30 \mathrm{~m} / \mathrm{s}$.

Acknowledgement Open Access funding provided by NTNU Norwegian University of Science and Technology (incl St. Olavs Hospital Trondheim University Hospital).

Open Access This article is licensed under a Creative Commons Attribution 4.0 International License, which permits use, sharing, adaptation, distribution and reproduction in any medium or format, as long as you give appropriate credit to the original author(s) and the source, provide a link to the Creative Commons licence, and indicate if changes were made. The images or other third party material in this article are included in the article's Creative Commons licence, unless indicated otherwise in a credit line to the material. If material is not included in the article's Creative Commons licence and your intended use is not permitted by statutory regulation or exceeds the permitted use, you will need to obtain permission directly from the copyright holder. To view a copy of this licence, visit http://creativecomm ons.org/licenses/by/4.0/.

\section{References}

Andersen OJ, Løvseth J (2006) The Frøya database and maritime boundary layer wind description. Mar Struct 19:173-192. https:// doi.org/10.1016/j.marstruc.2006.007.03

Bury KV (1975) Statistical models in applied science. Wiley, New York Chakrabarti SK (1990) Non-linear methods in offshore engineering. Elsevier, Amsterdam

Charnock H (1955) Wind stress on a water surface. QJR Meteorol Soc 81:639-640

Donkers JAJ, Brand AJ, Eecen PJ (2011) Offshore wind atlas of the Dutch part of the North Sea. In: Presented at the EWEA 2011, Brussels, Belgium, 14-17 March. https://www.ecn.nl/docs/ library/report/2011/m11031.pdf

Drennan WM, Taylor PK, Yelland MJ (2005) Parameterizing the sea surface roughness. J Phys Oceanogr 35:835-848

Faltinsen OM (1990) Sea loads on ships and marine structures. Cambridge University Press, Cambridge

Hsu SA (1974) A dynamic roughness equation and its application to wind stress determination at the air-sea interface. J Phys Oceanogr 4:116-120

Jones ISF, Toba Y (2001) Wind stress over the ocean. Cambridge University Press, Cambridge

Kalverla PC, Steeneveld G-J, Ronda RJ, Holtslag AAM (2017) An observational climatology of anomalous wind events at offshore meteomast IJmuiden (North Sea). J Wind Eng Ind Aerodyn 165:86-99. https://doi.org/10.1016/j.jweia.2017.10.003

Myrhaug D (2018) Some probabilistic properties of deep water wave steepness. Oceanologia 60(2):187-192. https://doi.org/10.1016/j. oceano.2017.10.003

Myrhaug D (2020) Comments regarding "Dependence of wind stress across an air-sea interface on wave states" by D. Zhao, M. Li. J Oceanogr. https://doi.org/10.1007/s10872-018-0494-9

Myrhaug D, Fouques S (2008) Bivariate distributions of significant wave height with characteristic wave steepness and characteristic surf parameter. In: Proc 27th Int Conf. on Offshore Mech and Arctic Eng, Estoril, Portugal, Paper No. OMAE2008-57728

Myrhaug D, Ong MC (2009) Effect of wave age on wind gust spectra over wind waves. ASME J Offshore Mech Arctic Eng 131:034501-1-034501-6 
Ochi MK, Shin YS (1988) Wind turbulent spectra for design considerations of offshore structures. In: Proc 20th Offshore Tech Conf, Houston, Texas, Paper No 5736 1;461-467

Powell MD, Vickery PJ, Reinhold TA (2003) Reduced drag coefficient for high wind speeds in tropical cyclones. Nature 422:279-283

Taylor PK, Yelland MJ (2001) The dependence of sea surface roughness on the height and steepness of the waves. J Phys Oceanogr 31:572-590
Zhao D, Li M (2019) Dependence of wind stress across an air-sea interface on wave states. J Oceanogr 75(3):207-223. https://doi. org/10.1007/s10872-018-0494-9

Publisher's Note Springer Nature remains neutral with regard to jurisdictional claims in published maps and institutional affiliations. 